\title{
Defined Eligibility Criterion
}

National Cancer Institute

\section{Source}

National Cancer Institute. Defined Eligibility Criterion. NCI Thesaurus. Code C93362.

An activity defined at a global library level that identifies one of a set of conditions that a subject must meet in order to participate in a study, or that a study subject must meet into order to participate in a certain part of the study. 